\title{
Relationship between nocturia and mortality: are we missing the forest for the trees?
}

\author{
Vincent Misraï ${ }^{1}$ Benoit Peyronnet ${ }^{2} \cdot$ Helene Charbonneau $^{3} \cdot$ David Attias $^{4} \cdot$ Atul Pathak $^{5}$
}

Received: 23 October 2018 / Accepted: 29 October 2018 / Published online: 28 November 2018

(c) Springer Nature Limited 2018

In their manuscript recently published in Prostate Cancer and Prostatic Disease Journal Bliwise et al. [1] explored, as several previous studies [2], the impact of nocturia on allcause mortality and found an increased mortality risk in men presenting with $\geq 3$ nocturia episodes/night. They concluded that nocturia was an independent predictive factor of mortality.

Although the authors have to be congratulated for the quality of their work, we would like to underscore several concerns that may question the reliability of their conclusion.

Firstly, the REDUCE trial was designed to determine whether dutasteride reduced the risk of incident prostate cancer among men who are at increased risk for the disease and the analysis of the effect of nocturia on mortality in men complaining from LUTS was not planned.

Secondly, the threshold they chose to define nocturia ( $\geq 3$ episodes per night) is not very much justified and might be called into question as it is not in line with the one from the International Continence Society ( $\geq 1 /$ night) nor with the most widely accepted to define clinically meaningful nocturia ( $\geq 2 / n i g h t)$ [3]. One may then wonder if the definition chosen could have been data-driven.

Another significant drawback is that nocturia was not documented with bladder diaries. Self-estimation by patients has been shown to be poorly reliable and commonly overestimating the number of nocturia episodes [4].

$\triangle$ Vincent Misraï

v.misrai@ clinique-pasteur.com

1 Department of Urology, Clinique Pasteur, Toulouse, France

2 Department of Urology, University of Rennes, Rennes, France

3 Department of Anesthesiology and Intensive Care Unit, Clinique Pasteur, Toulouse, France

4 Department of Pneumology, Clinique Pasteur, Toulouse, France

5 Department of Cardiology, Clinique Pasteur, Toulouse, France
It is then also impossible to determine the proportion of patients with nocturnal polyuria (NP) as an underlying cause of nocturia in this cohort.

The Medical Outcomes Study (MOS) sleep questionnaire has several limitations that Branche et al. [5] clearly acknowledged in their manuscript. One of the main shortcomings of the MOS questionnaire is that it is a poor tool to screen patients with obstructive sleep apnea (OSAS), a condition that can cause nocturnal polyuria by increasing atrial natriuretic peptide release secondary to hypoxia during apneic episodes. OSAS has been reported to be a common underlying etiology of nocturia [6]. Untreated/ undiagnosed OSAS can result in the occurrence of cardiovascular diseases, including coronary artery disease, hypertension, left ventricular dysfunction, and arrhythmias. Hence, OSAS may well be a significant driver of the relationship between nocturia and mortality. The lack of adjustment for this important confounder can be regarded as a significant limitation of the present report.

The pathophysiology of nocturia is far from being completely elucidated. Several cofactors such as nocturnal hypertension or primary sleep disorders have recently been suggested as possible contributors to nocturia pathogenesis and have just started being explored as such [7]. Even though the authors could not be blamed for lacking to adjust their analysis for these cofactors as their definitions and implications is not well defined nor standardized yet, these conditions may well play a significant role in the relationship between nocturia and mortality that will require to be further explored.

In conclusion, in addition to several other limitations, this study, as the previous ones exploring the impact of nocturia on overall mortality, may have missed important confounders, especially OSAS. The relationship between nocturia and mortality might not be that straightforward and we might be missing the forest for the trees. Further studies are needed to elucidate the comorbidities that may underpinned the relationship between nocturia and mortality. 
Author contributions Manuscript writing/editing: Vincent Misrai, Benoit Peyronnet. Manuscript reviewing: Hélène Charbonneau, Atul Pathak, and David Attias.

\section{Compliance with ethical standards}

Conflict of interest The authors declare that they have no conflict of interest.

\section{References}

1. Bliwise DL, Howard LE, Moreira DM, Andriole GL, Hopp ML, Freedland SJ. Nocturia and associated mortality: observational data from the REDUCE trial. Prostate Cancer Prostatic Dis. 2018. https://doi.org/10.1038/s41391-018-0090-5.

2. Fan Y, Wei F, Lang Y, Qi W. Meta-analysis of nocturia and risk of all-cause mortality in adult population. Int J Cardiol. 2015;195:120-2.
3. Tikkinen KAO, Johnson TM, Tammela TLJ, Sintonen H, Haukka $\mathrm{J}$, Huhtala $\mathrm{H}$, et al. Nocturia frequency, bother, and quality of life: how often is too often? A population-based study in Finland. Eur Urol. 2010;57:488-96.

4. Ku JH, Hong SK, Kim HH, Paick J-S, Lee SE, Oh S-J. Is questionnaire enough to assess number of nocturic episodes? Prospective comparative study between data from questionnaire and frequency-volume charts. Urology. 2004;64:966-9.

5. Branche BL, Howard LE, Moreira DM, Roehrborn C, CastroSantamaria R, Andriole GL, et al. Sleep problems are associated with development and progression of lower urinary tract symptoms: results from REDUCE. J Urol. 2018;199:536-42.

6. Misraï V, Charbonneau H, Attias D, Pathak A. Obstructive sleep apnea syndrome should always be screened in patients complaining of nocturia. World J Urol. 2018. https://doi.org/10.1007/s00345018-2534-x.

7. Everaert K, Hervé F, Bower W, Djurhuus JC, Dmochowski R, Fine $\mathrm{N}$, et al. How can we develop a more clinically useful and robust algorithm for diagnosing and treating nocturia? ICI-RS 2017. Neurourol Urodyn. 2018;37:S46-S59. 